\title{
0402 TRAUMA DEATHS MAGNITUDE IN A STATE OF MEXICO: ACTIVE VERSUS PASSIVE INJURY SURVEILLANCE SYSTEM
}

J E Penuelas*, J E Verdugo-Correa, J A Gil- Pineda, M G RamirezZepeda Correspondence: Secretaria de Salud de Sinaloa, Insurgentes s/n Centro Sinaloa, Culiacan, Sinaloa, 80129, Mexico

10.1136/ip.2010.029215.402

Introduction Recent estimations of the magnitude of deaths by traffic accidents in Mexico, question the reliability of the official data of the Informatics, Geography and Statistics National Institute, about trauma deaths (Passive Surveillance System).

Objective To determine the magnitude of trauma deaths in a state of Mexico, through an active epidemiological surveillance system, and compare it with the one officially reported.

Material and methods In 2007, we registered the deaths by injuries in the state of Sinaloa (2.64 millions of people, US\$5400 GDP per capita), using five sources of information: death certificates, press reports, hospital records, traffic police reports and the brief of the Department of Justice.

Each case was compared to avoid duplicity and verified for at least two sources. We got the totals, and by external cause according to the ICD-10, and we compared them with the official information.

Results We got, through the active surveillance, 1985 trauma deaths, versus 1826 from the official data.

Important differences were found in the following: accidents 1173 versus 1327, traffic accidents 767 versus 546, falls 137 versus 21 , accidents by firearm 10 versus 180 and homicides 706 versus 402.

Conclusions The magnitude of trauma deaths determined by an active injury surveillance system is $9 \%$ higher than the one reported by the passive system (official information). The difference between the magnitudes according to external cause are even more accentuated. We recommend the active injury surveillance system to determine the real magnitude of the problem in Mexico. 